\title{
Oral Manifestations in Patients with Psoriasis: A Cross-Sectional Study
}

\author{
Amir Ehsani ${ }^{1}$, Hosein Mortazavi ${ }^{1}$, Pedram Nourmohamadpure ${ }^{1}$, Arghavan Azizpour ${ }^{1}$, Mahbubeh \\ Janesar Hoseinie ${ }^{1}$ and Forugh Ghaedi ${ }^{1, *}$ \\ ${ }^{1}$ Department of Dermatology, Tehran University of Medical Sciences, Tehran, Iran \\ "Corresponding author: Department of Dermatology, Tehran University of Medical Sciences, P.O. Box: 1199663911, Tehran, Iran. Tel: +98-9124652658, Email: \\ forugh_ghaedi@yahoo.com
}

Received 2018 September 05; Accepted 2018 September 06.

\begin{abstract}
Background: The exact prevalence and distinct clinical and histological criteria of psoriatic lesions in the oral cavity remain unknown. Although some non-specific lesions are more frequent in psoriatic patients in comparison with healthy people, the incidence and clinical variation of psoriasis are heterogeneous in the literature.

Objectives: This study aimed to evaluate the incidence of oral lesions in Iranian patients with psoriasis.

Methods: Patients with plaque-type psoriasis were participated in a cross-sectional study. Physicians performed full-body skin examination and assessed extra-cutaneous involvement including oral cavity, nails and articular system.

Results: One hundred patients with psoriasis ( 41 males and 59 females) with the mean age of $43.79 \pm 12.52$ years were participated in the study. Mucosal changes clinically suggestive of oral psoriasis were detected in none of the cases. We observed nonspecific oral lesions in $48 \%$ of the patients including fissured tongue (35\%), angular cheilitis (13\%), actinic cheilitis (11\%), geographic tongue (6\%), fibroma (3\%) and denture stomatitis (2\%). The statistical analyses showed that presentation of oral lesions increases with concomitant cardiovascular disorders or diabetes mellitus, but no relationship between oral lesions and other demographic and clinical data was noted.

Conclusions: Although the incidence of true oral psoriasis is rare, non-specific oral lesions may be frequently found in patients with psoriasis. Since both true psoriatic oral lesions and non-specific changes are mostly asymptomatic, routine examination of the oral cavity is necessary in all patients with the diagnosis of psoriasis.
\end{abstract}

Keywords: Psoriasis, Oral Lesions, Oral Manifestations, Oral Cavity

\section{Background}

Psoriasis is a common dermatologic disease that is estimated to affect approximately $2 \%$ of the population (1). Cutaneous manifestations of psoriasis are well defined as well as prevalence and clinical subtypes of some extracutaneous manifestations including psoriatic nails and psoriatic arthritis $(2,3)$.

For many years, it was assumed that psoriasis does not involve the oral cavity, until 1903, that Oppenheim for the first time described oral psoriasis based on biopsy of a buccal mucosal lesion in a patient with cutaneous psoriasis (4). Since then, several reports have described oral involvement with varied clinical features including generalized, plaque-type, striate, patchy or papular erythematous or white lesions in patients with cutaneous psoriasis (5-9). Biopsy from most of these lesions demonstrated a psoriasiform pattern that was in concordance with the diagnosis of oral psoriasis.

However, knowledge about oral psoriasis is generally limited and based on case reports because of the low incidence of psoriatic lesions in the oral cavity. Bruce et al. explained that the asymptomatic nature of these lesions is the reason for the lower prevalence of oral lesions in psoriasis compared to other papulosquamous diseases (10). Furthermore, normal epithelial turnover is 28 days, but in psoriatic cutaneous plaques it decreases to 3 to 7 days, which is close to the normal regenerative time of the oral epithelium, thus, this phenomenon may be the cause of the lower prevalence of apparent changes in the oral mucosa of patients with psoriasis (11). On the other hand, few recent surveys have reported controversy over the existence of oral psoriasis as a distinct entity (12) and considered oral findings as psoriasiform mucositis rather than oral psoriasis (13).

Consequently, the exact prevalence and distinct clinical and histological criteria of oral manifestations in psoriasis remain unknown (14). Despite the low prevalence of true oral psoriasis, some nonspecific lesions seem to be 
more frequent in psoriatic patients in comparison with healthy population, but the incidence and clinical findings are heterogeneous in the literature (15-18).

\section{Objectives}

This study sought to evaluate the incidence of oral lesions in Iranian patients with psoriasis.

\section{Methods}

\subsection{Participants}

Samples were collected from individuals referred to outpatient clinics and hospitalized wards of dermatology in Razi Hospital, Tehran, Iran, from January 2015 to April 2016. Patients affected with plaque-type psoriasis aged between 20 and 80 years were enrolled in this cross-sectional study through convenience sampling method. The diagnosis of psoriasis was made mainly based on clinical data, although it was approved by pathologic assay in some cases. Patients suffering from any concurrent systemic or dermatologic diseases that affect the oral cavity such as lichen planus, lupus erythematosus, pemphigoid and pemphigus were excluded.

\subsection{Instruments}

Patients filled out a checklist for demographic and clinical data including history of diabetes mellitus and cardiovascular diseases. The skin was examined and involvement of body surface was reported in six groups, namely $<10 \%$, $10 \%-29 \%, 30 \%-49 \%, 50 \%-69 \%, 70 \%-89 \%$ and $90 \%-100 \%$. Physician performed complete physical examination for each patient in order to evaluate extra-cutaneous involvement including oral cavity, nails and articular system. Diagnosis of oral findings was based on clinical features.

\subsection{Statistical Analysis}

Data were analyzed by using SPSS, version 22. Frequency means and standard deviations were reported. Independent t-test was used to compare mean scores between discontinuous variables, and Pearson's correlation coefficient was run to evaluate the correlation between continuous variables. P value less than 0.05 was considered statistically significant.

\subsection{Ethical Considerations}

Each patient filled out a written informed consent form, and the Ethics Committee of Tehran University of Medical Sciences approved this study.

\begin{tabular}{|cc|}
\hline Table 1. The Frequency of Associated Conditions in Psoriasis Patients \\
\hline Concomitant Conditions & Frequency (\%) \\
\hline Oral involvement & 48 \\
\hline Yes & 52 \\
\hline No & \\
\hline Nail involvement & 39 \\
\hline Yes & 61 \\
\hline No & \\
\hline Articular involvement & 28 \\
\hline Yes & 72 \\
\hline No & \\
\hline Smoking & 19 \\
\hline Yes & 81 \\
\hline No & 22 \\
\hline Positive medical history & 78 \\
\hline Yes & \\
\hline No & \\
\hline Cardioval & \\
\hline
\end{tabular}

${ }^{\mathrm{a}}$ Cardiovascular disease or diabetes mellitus.

\begin{tabular}{lc}
\hline Table 2. The Frequency of Oral Findings in Psoriasis Patients \\
\hline Oral Lesions & Frequency (\%) \\
\hline Fissured tongue & 35 \\
\hline Angular cheilitis & 13 \\
\hline Actinic cheilitis & 11 \\
\hline Geographic tongue & 6 \\
\hline Fibroma & 3 \\
\hline Denture stomatitis & 2 \\
\hline
\end{tabular}

\section{Results}

One hundred patients with psoriasis (41 males and 59 females) with the mean age of $43.79 \pm 12.52$ years were participated in the study. The mean age of disease onset and its mean duration were $31.24 \pm 13.45$ and $12.55 \pm 9.58$ years, respectively. Table 1 shows demographic and clinical data of the patients.

All the patients had plaque-type psoriasis and involvement of body surface area included: Less than $10 \%$ (11\%), $10 \%$ - 29\% (8\%), 30\% - 49\% (7\%), 50\% - 69\% (12\%), 70\% - 89\% (19\%), and $90 \%-100 \%$ (43\%). The medical history and/or physical examination of nail involvement and psoriatic arthritis were positive in $39 \%$ and $28 \%$ of the patients, respectively; overall, $48 \%$ of the patients had oral lesions. Table 2 shows the frequency of oral lesions.

The statistical analyses showed no relationship between presence of oral lesions in patients with plaque-type 
psoriasis and demographic data and clinical indexes including extension of cutaneous lesions, nail involvement and psoriatic arthritis. Incidence of oral lesions was significantly higher in patients with concomitant cardiovascular diseases or diabetes mellitus $(\mathrm{P}=0.038)$.

\section{Discussion}

The present study indicated the incidence of oral finding in $48 \%$ of 100 patients with psoriasis. The frequency of oral lesions in our participants was reasonable and corresponded with previous reports, which observed oral lesions in 34\% - 67.5\% of patients with psoriasis $(6,16-18)$.

Despite the high prevalence of nonspecific oral lesions in our samples, none of our cases had mucosal changes that were clinically suggestive of oral psoriasis. However, reports of true psoriatic oral lesions are rare, which may be due to undetectable and transient nature of mucosal psoriatic lesions (10). There are few case reports of pathologically-approved psoriatic oral lesions in the literature (7-9). Hietanen et al. reported oral lesions, mostly erythematous areas, in 20 out of 200 cases, and histopathologic survey showed typical psoriatic tissue pattern only in of 4 of 20 patients concomitant with oral psoriasis (6).

We detected nonspecific lesions including fissured tongue (35\%), angular cheilitis (13\%), actinic cheilitis (11\%), geographic tongue (6\%), fibroma (3\%) and denture stomatitis $(2 \%)$ in our samples.

The most common lesion detected in our samples was fissured tongue (35\%), although primitive studies reported lower prevalence of this lesion $(6,19)$. However, recent controlled studies considered fissured tongue as one of the most prevalent oral lesions in psoriasis patients. Similarly, Daneshpazhooh et al. found fissured tongue as the most frequent (33\%) oral lesion among 200 psoriatic patients (18). Since then several studies have reported the same results, for instance, Hernandez-Perez et al. reported a statistically significant increase in fissured tongue among psoriatic patients (47.5\%) compared to controls (20.4\%) (16). Costa et al. observed fissured tongue as the most prevalent lesion (34.3\%) in a sample of 166 psoriasis patients, they showed the prevalence of fissured tongue increase significantly by age, but we did not detect any relationship between oral findings and demographic data (17).

Geographic tongue is a chronic and inflammatory disorder with unknown etiology detected in $1 \%$ - $2 \%$ of the general papulation $(20,21)$. Similarity in histological pattern and genetic basis (22) of geographic tongue and psoriasis is assumed, which may suggest these two entities may be the same. We detected geographic tongue in $6 \%$ of the patients compatible with previous studies, which reported a prevalence of $5 \%-19 \%(7,15-19,23)$.
Similar to our results, Morris et al. detected no relationship between disease extension and presentation of geographic tongue (7), but Daneshpazhooh et al. observed an increase in the frequency of geographic tongue with increasing psoriasis area severity index score (18).

The next prevalent oral lesions detected in our samples were angular cheilitis (13\%) and actinic cheilitis (11\%). Lip psoriasis may mimic clinical features of chronic eczema, actinic dermatitis, chronic candidiasis or leukoplakia, which can lead to delayed diagnosis (24). It may be the reason for the high prevalence of lip dermatoses that we observed in this study. In doubtful instances, biopsy may be helpful in accurate diagnosis and management.

Costa et al. reported the frequency of fibroma and denture stomatitis as $2.4 \%$ and $7.8 \%$ in patients with psoriasis, respectively (17). We observed fibroma and denture stomatitis in $3 \%$ and $2 \%$ of the patients, respectively. Furthermore, oral lesions in psoriasis increased with concomitant cardiovascular diseases or diabetes mellitus in this study. Similarly, investigations showed that denture stomatitis and irritated fibroma are more frequent in patients with diabetes mellitus (25).

The limitation of the study was the small sample size that impacted the interpretation of our findings. Detection of true rare oral psoriasis lesions and assessment of their relationship with disease severity needs larger sample sizes involving a control group and evaluation a standard severity score. Biopsy from oral lesions can provide further information regarding oral involvement in patients with psoriasis.

\subsection{Conclusions}

Although the incidence of true oral psoriasis is rare, nonspecific oral lesions may be frequently found in patients with psoriasis. Since true psoriatic oral lesions and nonspecific changes are mostly asymptomatic, routine examination of the oral cavity seems necessary in all patients with the diagnosis of psoriasis.

\section{Footnotes}

Conflict of Interest: The authors declare that they have no conflict of interest.

Funding/Support: This work was supported by Tehran University of Medical Sciences.

Ethical Considerations: Each patient filled written informed consent and The Ethical Committee in Tehran University of Medical sciences approved this study. 


\section{References}

1. Christophers E. Psoriasis epidemiology and clinical spectrum. Clin Exp Dermatol. 2001;26(4):314-20. [PubMed:11422182].

2. Van De Kerkhof PC, Nestle FO. psoriasis. In: Bolognia JL, Jorizzo JL, Schaffer JV, editors. Dermatology. 3th ed. Philadelphia: Elsevier; 2012.

3. Radtke MA, Reich K, Blome C, Rustenbach S, Augustin M. Prevalence and clinical features of psoriatic arthritis and joint complaints in 2009 patients with psoriasis: Results of a German national survey. J Eur Acad Dermatol Venereol. 2009;23(6):683-91. doi: 10.1111/j.14683083.2009.03159.x. [PubMed: 19309433].

4. Oppenheim M. Psoriasis vulgaris der mundschleimhaut. Monatsschr Prakt Dermatol. 1903;37:489-96.

5. Salmon TN, Robertson GR, Tracy NH, Hiatt WR. Oral psoriasis. Oral Surg Oral Med Oral Pathol.1974;38(1):48-54. [PubMed: 4525672].

6. Hietanen J, Salo OP, Kanerva L, Juvakoski T. Study of the oral mucosa in 200 consecutive patients with psoriasis. Scand J Dent Res. 1984;92(1):50-4. [PubMed: 6585911].

7. Morris LF, Phillips CM, Binnie WH, Sander HM, Silverman AK, Menter MA. Oral lesions in patients with psoriasis: A controlled study. Cutis. 1992;49(5):339-44. [PubMed:1521493]

8. Ulmansky M, Michelle R, Azaz B. Oral psoriasis: Report of six new cases. J Oral Pathol Med. 1995;24(1):42-5. [PubMed: 7722920].

9. Younai FS, Phelan JA. Oral mucositis with features of psoriasis: Report of a case and review of the literature. Oral Surg Oral Med Oral Pathol Oral Radiol Endod. 1997;84(1):61-7. [PubMed: 9247953].

10. Bruce AJ, Rogers RS. Oral psoriasis. Dermatol Clin. 2003;21(1):99-104. [PubMed: 12622272].

11. Auerbach R. Newer knowledge of psoriasis. Postgrad Med. 1969;46(6):89-91. [PubMed: 5352937].

12. Yesudian PD, Chalmers RJ, Warren RB, Griffiths CE. In search of oral psoriasis. Arch Dermatol Res. 2012;304(1):1-5. doi: 10.1007/s00403-0111175-3. [PubMed: 21927905].

13. Reis V, Artico G, Seo J, Bruno I, Hirota SK, Lemos C, et al. Psoriasiform mucositis on the gingival and palatal mucosae treated with retinoicacid mouthwash. Int J Dermatol. 2013;52(1):113-5. doi: 10.1111/j.13654632.2010.04739.x. [PubMed: 23278619].

14. Mattsson $U$, Warfvinge $G$, Jontell M. Oral psoriasis-a diagnostic dilemma: A report of two cases and a review of the literature. Oral Surg Oral Med Oral Pathol Oral Radiol. 2015;120(4):e183-9. doi: 10.1016/j.oooo.2015.03.005. [PubMed: 25944682].
15. Babu RA, Chandrashekar P, Kumar KK, Reddy GS, Chandra KL, Rao V, et al. A study on oral mucosal lesions in 3500 patients with dermatological diseases in South India. Ann Med Health Sci Res. 2014;4(Suppl 2):S84-93. doi: 10.4103/2141-9248.138019. [PubMed: 25184094]. [PubMed Central: PMC4145524].

16. Hernandez-Perez F, Jaimes-Aveldanez A, Urquizo-Ruvalcaba Mde L, Diaz-Barcelot M, Irigoyen-Camacho ME, Vega-Memije ME, et al. Prevalence of oral lesions in patients with psoriasis. Med Oral Patol Oral Cir Bucal. 2008;13(11):E703-8. [PubMed: 18978710].

17. Costa SC, Hirota SK, Takahashi MD, Andrade H, Migliari DA. Oral lesions in 166 patients with cutaneous psoriasis: A controlled study. Med Oral Patol Oral Cir Bucal. 2009;14(8):e371-5. [PubMed: 19300356].

18. Daneshpazhooh M, Moslehi H, Akhyani M, Etesami M. Tongue lesions in psoriasis: A controlled study. BMC Dermatol. 2004;4(1):16. doi: 10.1186/1471-5945-4-16. [PubMed: 15527508]. [PubMed Central: PMC538751].

19. Buchner A, Begleiter A. Oral lesions in psoriatic patients. Oral Surg Oral Med Oral Pathol.1976;41(3):327-32. [PubMed: 1061920].

20. Weathers DR, Baker G, Archard HO, Burkes EJ. Psoriasiform lesions of the oral mucosa (with emphasis on "ectopic geographic tongue"). Oral Surg Oral Med Oral Pathol. 1974;37(6):872-88. [PubMed: 4524888].

21. Shulman JD, Carpenter WM. Prevalence and risk factors associated with geographic tongue among US adults. Oral Dis. 2006;12(4):381-6. doi: 10.1111/j.1601-0825.2005.01208.x. [PubMed: 16792723].

22. Gonzaga HF, Torres EA, Alchorne MM, Gerbase-Delima M. Both psoriasis and benign migratory glossitis are associated with HLA-Cw6. Br J Dermatol.1996;135(3):368-70. [PubMed: 8949427].

23. Pogrel MA, Cram D. Intraoral findings in patients with psoriasis with a special reference to ectopic geographic tongue (erythema circinata). Oral Surg Oral Med Oral Pathol. 1988;66(2):184-9. doi: 10.1016/00304220(88)90091-6. [PubMed: 3174052].

24. Rahman MA, Fikree M. Perioral psoriasis.J Eur Acad Dermatol Venereol. 2000;14(6):521-2. doi: 10.1046/j.1468-3083.2000.00170-7.x. [PubMed: 11444285].

25. Guggenheimer J, Moore PA, Rossie K, Myers D, Mongelluzzo MB, Block $\mathrm{HM}$, et al. Insulin-dependent diabetes mellitus and oral soft tissue pathologies. I. Prevalence and characteristics of non-candidal lesions. Oral Surg Oral Med Oral Pathol Oral Radiol Endod.2000;89(5):563-9. doi: 10.1067/moe.2000.104476. [PubMed: 10807712]. 